\title{
Principles \& Outcome of treatment by Titanium Elastic Nails for Diaphyseal fracture of femur in Children.
}

\author{
Dr.Vivek A.Patel ${ }^{1}$, Dr.J.J.Patwa ${ }^{2}$, Dr.R.N.Panchal ${ }^{3}$, Dr.Shantanu Jain ${ }^{4}$ \\ ${ }^{I}$ Assistant Professor of orthopaedics, Department of orthopedics, Pramukh Swami medical college and Shree \\ Krishna hospital, Karamsad,Anand, Gujarat,India. \\ ${ }^{2}$ Ex-Professor \& Head of the Department, Department of orthopaedics, Pramukh Swami medical college and \\ Shree Krishna hospital, Karamsad, Anand, Gujarat,India. \\ ${ }^{3}$ Professor \& Head of the Department, Department of orthopaedics, Pramukh Swami medical college and Shree \\ Krishna hospital, Karamsad,Anand, Gujarat,India. \\ ${ }^{4}$ Post Graduate,Department of orthopaedics,Pramukh Swami medical college and Shree Krishna \\ hospital,Karamsad,Anand, Gujarat,India.
}

\begin{abstract}
For treatment of pediatric femur shaft fractures in Children of age less than five years; there has been no controversy prevails and can be best treated by traction followed by cast method as proved by number of studies because of early union and rapid remodeling. Children with age higher than five years have more chances of malunion and plaster complication. Our study on pediatric diaphyseal femoral fractures at these age group shows good outcome with closed reduction and fixation by Titanium Elastic Intramedullary Nails; as compare to traditional methods like conservative traction followed by cast method, open reduction and plate fixation, external fixator as they have their possible drawbacks in results described by conventional studies.
\end{abstract}

Key Words: Titanium Elastic Nail (TEN), Diaphyseal, Femur.

\section{Introduction:}

Healing is a biological process helped by mechanical stability ${ }^{1}$.Pediatric femoral shaft fractures as an incapacitating injury is still an inexact science with many methods of treatment, so lots of controversy prevails. In the recent century the focus has shifted from anatomical fixation to biological fixation of all fractures. Girdlestone warned that, there is danger inherent in the mechanical efficiency of our modern methods; danger lets the craftsmen forget that union cannot be imposed but may have to be encouraged ${ }^{1}$.

It has been agreed that stress ${ }^{1}$ across the site of the fracture promotes union. The perceived advantage of Titanium elastic nailing includes early union due to repeated micromotion ${ }^{2}$ at fracture site. Above six years of age when femoral shaft fractures in children treated nonoperatively could have; loss of reduction, malunion, intolerance and complications associated with plaster ${ }^{4}$.The treatment traditionally influenced by type of injury, associated injuries, age related, type and the location of the fracture. Excluding the controversy for treatment of paediatric shaft femur fractures between the age group sixth to sixteen years the solely outcomes of TEN are yet to be more studied.

\section{Material And Methods:}

We have treated 15 pediatric patients between age group of 5 to 15 years of femur fractures by Titanium Elastic Nail at our Institute between January 2007 to January 2009. Each case was followed up to radiological union and subsequent follow up was done after 6-12 months postoperatively. AO fracture Fracture classification was followed. Results were evaluated on the basis of 1) Clinical Result - Absence of local tenderness and pain on stressing the fracture site or on bearing the weight fully on the operated limb as single leg weight bearing which must be painless at fracture site. Other criteria followed were Fracture angulations, Limb length discrepancy \& Range of motion. 2) Radiological Union - Presence of callous around the fracture circumference with density similar or more to that of adjacent cortex or obliteration of fracture line whichever was earlier.

In the Current study of 15 patients; $60 \%$ cases were males where as $40 \%$ cases females. In male patients 8 were closed fractures while 1 patient had open fracture. In female patients all were closed fractures. $53.33 \%$ cases had age between $6-10$ years out of which 4 males \& 4 females. $46.66 \%$ cases had age between 10- 15 years out of which 5 males \& 2 females (TABLE 1). Minimum age was 6 and maximum age was 15 years. 8 patients sustained road traffic accidents, while 7 patients sustained injury by fall from height or fall while walking. 
Table.1:

\begin{tabular}{|l|l|l|l|}
\hline Age & Patients & Males & Females \\
\hline $6-10$ years & $53.33 \%$ & 4 & 4 \\
\hline $10-15$ years & $46.66 \%$ & 5 & 2 \\
\hline
\end{tabular}

\section{Operative Technique:}

In supine position on fracture table insertion point for retrograde entry of TEN on the femur is two to three centimeter proximal to the epiphyseal plate just above the knee to be checked under image intensifier television. After putting skin incisions fascia lata divided and bony entry is made by owl. Nails can be prebend that vertex of bend comes at fracture. Medial as well as lateral retrograde entry of the nail must be simultaneous and both the nails should pass the fracture site nearly simultaneous to prevent angulation at the fracture site. Generally two nails of same thickness are used. Variations in the entry site like antegrade can be chosen rarely if one of the cortex distally found much comminuted to hold the retrograde TEN at entry side.

\section{Results:}

Radiological union occurred at an average of 8.5 weeks. Full weight bearing was permitted after elicited clinical non tenderness over the fracture site at an average of 9 weeks. Mobilization was permitted at an average of $5^{\text {th }}$ Post op. day. 3 cases were mobilized at slight delay because of associated co morbidities at 1 week and 12 cases were mobilized at $3-4^{\text {th }}$ Post Operative day. Limb length discrepancies were $<5 \mathrm{~mm}$ in all the cases. Limb Lengthening were observed in 12 cases which were less than $5 \mathrm{~mm}$; whereas shortening were observed in 3 cases which were also less than $5 \mathrm{~mm}$ and clinically non significant; at the union time (TABLE 2). No clinically significant varus / valgus/ other angulation in any cases. Then when we called them 6-12 months postoperatively 12 cases were contactable and came for evaluation with radiologically consolidated and remodeled fracture (Fig.1, Fig.2).No clinically significant angulations. Limb length discrepancies found same as stated above. Average range of motion were almost full extension upto normal flexion i.e. more than 120 degrees. No case had any signs of infection. In one case prominent tip of Titanium Elastic nail was found protruding just beneath the skin over the anterolateral part just above the knee and patient subsequently was taken for implant extraction.

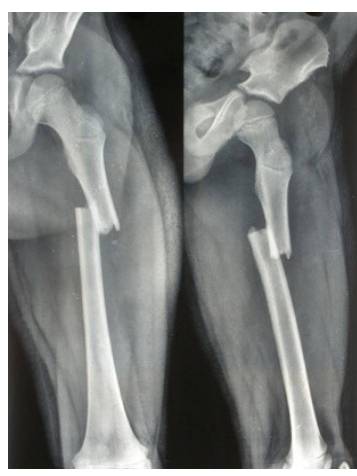

Pre Op. X-ray(Case1)

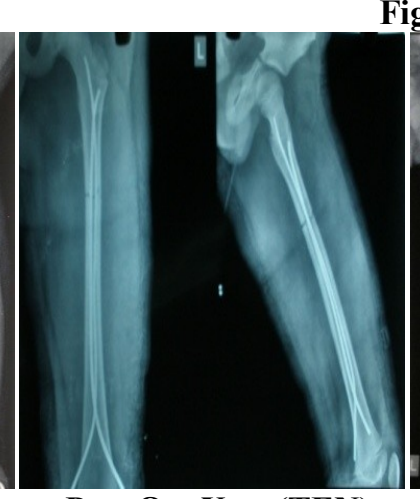

Post Op. Xray(TEN)

Fig.1:

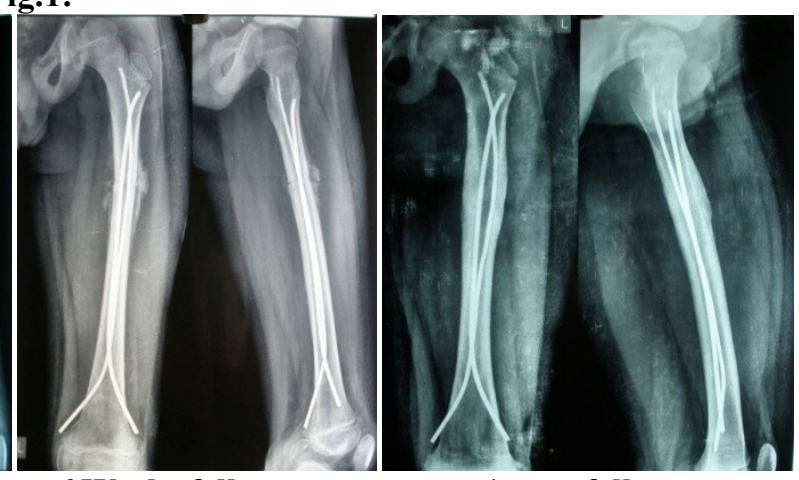

6 Weeks follow up.
1 year follow up.

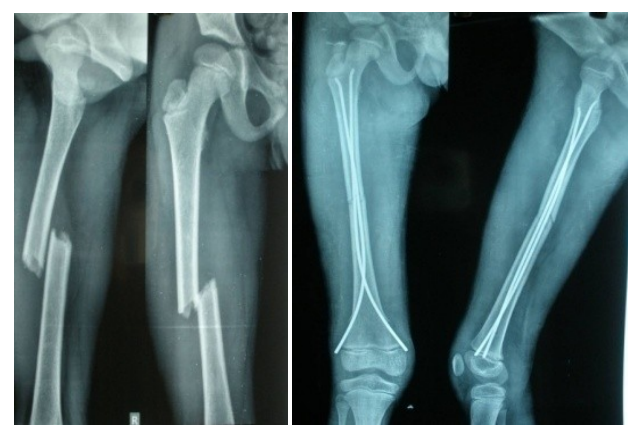

Pre Op. X-ray(Case 2) Post Op. Xray
Fig.2:
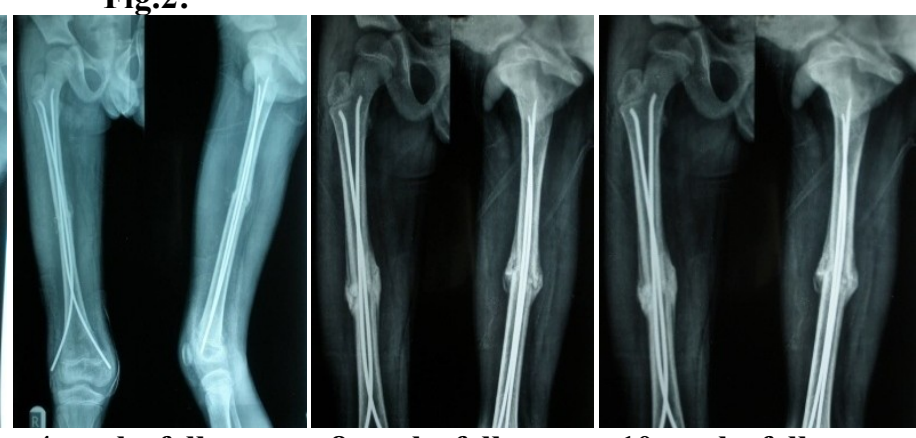

4 weeks follow up. 8 weeks follow up. 10 weeks follow up. 
Table.2:

\begin{tabular}{|l|l|l|}
\hline Measurement & Patients & $\begin{array}{l}\text { Limb length } \\
\text { discrepancy }\end{array}$ \\
\hline Limb lengthening & $\mathbf{8 0} \%$ & $<5 \mathrm{~mm}$ \\
\hline Limb shortening & $\mathbf{2 0} \%$ & $<5 \mathrm{~mm}$ \\
\hline
\end{tabular}

\section{Discussion:}

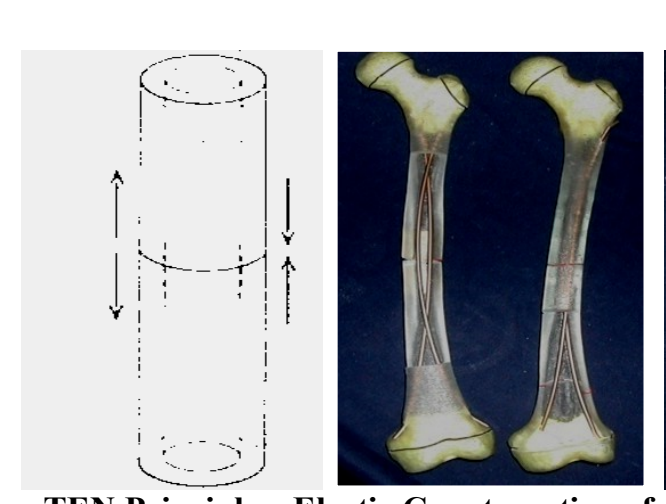

Fig.3:

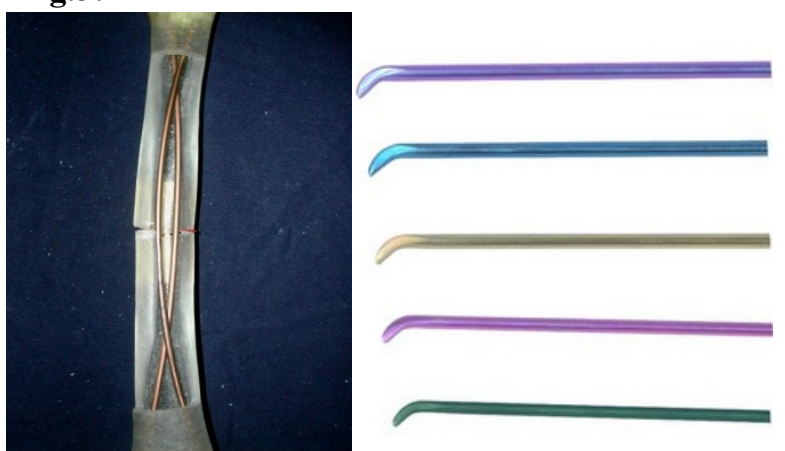

TEN Principles: Elastic Counteraction of accentric loading on femur, Three Point Fixation.

Titanium Elastic Nail is a Elastic Stable Intramedullary Nail.It works on the principle of symmtric Bracing action of two elastic nails having same modulous of elasticity; which causes three point fixation $\&$ gives rotational,Axial,Transational and Bending Stability by counteracting the distraction and compression forces working on diaphysis of femur(Fig.3).

TD Bhattacharya, SK Bhuyan, KC Saikia et al. says that; Titanium Elastic Nail (TEN) does not provide adequate stability in comminuted, long oblique or spiral fractures or even if it is contemplated post Operative immobilization is essential ${ }^{5}$.Transverse, short oblique, short spiral with minimum comminution are best indications. There are no enough comparative studies regarding efficacy between Enders nail ${ }^{3}$, Rush nail and TEN exist. Risk of complication of operative procedure is always there ${ }^{2}$.

Studies have found that TEN is advantageous over hip spica in femoral shaft fracture in children as a treatment method ${ }^{9}$. Advantages of TEN are reduced hospitalization ${ }^{12}$ and early mobilization. The result of Femoral Intramedullary Nail done in preschool children will achieve recovery milestones much faster than those treated with traction and spica cast study of 72 cases $^{7}$.TEN is indicated in all femoral diaphyseal fractures of children above 6 years till physeal closure ${ }^{8}$.This study found TEN more better option as cost benefit than traditional traction followed by cast method for less hospital stay and early return to walk.

Eventhough drawbacks of this method over other methods of treatment are of cause the issue of just narration $^{10}$. Two operations one for insertion and one for removal of implant are needed. Although the authors are still inclined to removal of Femur Intramedullary Nail in most of patients, the need for routine elective execution of this is questionable. In severely comminuted fractures role of TEN versus Traction and cast is the issue of debate. Chance for entry site irritation ${ }^{6}$, skin erosion and septic arthritis are noted as per the other studies done $\mathrm{s}^{5}$.

Important advantages are that the periosteum is not disturbed and being a closed procedure there is no disturbance of fracture hematoma so chance of infection is less. TEN as a retrograde technique of nailing have less chances of AVN of femoral head ${ }^{11}$.

\section{Conclusion:}

Pediatric femoral shaft fractures can be treated by number of methods; out of that and especially amongst the surgical methods closed Titanium elastic nailing has evolved as a good method, more for nearly stable fractures; reducing the financial, immobilization and psychological burden to the patient and relatives. As far as surgeon is concerned one should be well aware of biomechanics of individual fracture and technique. No significant chance of malunion with fewer chances of clinically significant limb length discrepancy \& respect to the physis maintains as a preliminary outcome shows in our study. TEN permits early partial weight bearing with minimal stress shielding and early rehabilitation of nearby joints concurrently. 
Our study has strong inference that closed titanium elastic nailing gives biological environment along with optimal mechainical stability with permitted micro motion at fracture site resulting in more consolidation of fracture and high union rate with minimum complications and minimum limb length discrepancy especially in particular age group of pediatric femoral shaft fractures.

\section{References}

[1] R J Brumback, Intramedullary nailing of femoral shaft fractures part 2. Fracture healing with static interlocking fixation JBJS 70A, $1988,1453-1462$.

[2] GOODSHIP A.E. The influence of induced micromovement upon the healing of experimental tibia fractures. JBJS 67B (4): 1985, 650-655.

[3] Ender H.G., Subtrochantere Bruchedes Oberschenkeis:behandlung mit Federnagelen.Chir.9:359,1974.

[4] Flynn J.M., Luedtke L.M., Ganley T.J.,Dawson J.,Davidason R.S.,Dormans J.P.,Ecker M.L.,Greg J.R.,Horn B.D.,Drummond D.S., Comparison of titanium elastic nails with traction and spica cast to treat femoral fracturesin children, J Bone \& Joint Surg. Am., 2004(86 A):770-777.

[5] K.C.Saikia,S K Bhuyan, T.D. Bhattacharya, Titanium elastic nailing in femoral diaphyseal fractures of children in 6-16 years of age. IJO 2007, vol.41, issue 4,381-385.

[6] Flynn JM.Hresko T,Reynolds RA,Blasier RD,Davidson R, Kasser J. Titanium elastic nails for pediatric femur fractures: A multicenter study of early results with analysis of complications. JPediatric Orthop. 2001; 21:4-8.

[7] Bopst.L.,Reinberg O.,Lutz N., Femur fracture in preschool children: experience with flexible intramedullary nailing in 72 children.,J. Pediatr Orthop,2007: (27): 299-303.

[8] Lascombes P, Haumont T, Journeau P,Use and abuse of flexible intramedullary nailing in children and adolescents, J Pediaric Orthop, 2006 (26):827-34.

[9] Buechsenschuetz KE,Mehlman CT, Shaw KJ, Crawford AH, Immerman EB. Femoral shaft fractures in children: Traction \& cast versus elastic stable intramedullary nailing. J Trauma $2002:(53): 914-21$.

[10] Luhmann SJ, Schootman M, Schoenecker PL, Dobbs MB,Gordon JE. Complications of titanium elastic nails for pediartric femoral shaft fractures. J Pediatr Orthop. 2003 Jul-Aug; 23(4): 443-447.

[11] Vierhout B.P.,Sleeboom C.,Aronson D.C., Van Walsum A.D.,Zilp G.,Heij H.A.,Long term outcome of elastic stable intramedullary fixation of femoral fractures in children. Eur J Pediatr Surg, 2006 (16): 432-437.

[12] Herndon WA, Mahnken RF,Yngve DA, Sullivan JA. Management of femoral shaft fractures in adolescents.J Peditr Orthop. 1989; 9:29-32. 